\title{
Maturidade fisiológica de sementes de tungue (Aleurites fordii Hemsl.)
}

\author{
Physiological maturity of seeds tung trees (Aleurites fordii Hemsl.)
}

\section{Paulo Ricardo Lima ${ }^{1 *}$, Augustinho Borsoi ${ }^{2}$, Paulino Ricardo Ribeiro dos Santos ${ }^{1}$, João Alexandre Lopes Dranski $^{1}$, Ubirajara Contro Malavasi ${ }^{1}$ e Marlene de Matos Malavasi ${ }^{1}$}

Recebido em 13/01/2016 / Aceito em 01/08/2016

\section{RESUMO}

O ensaio objetivou determinar a maturidade fisiológica de sementes de tungue (Aleurites fordii Hemsl.) em função da coloração dos frutos. Frutos de dez árvores com quatro anos de idade foram coletados em Cascavel, PR. O ensaio seguiu o delineamento inteiramente casualizado, com quatro estádios de maturação dos frutos e cinco repetições com 25 sementes cada. Os frutos foram classificados em três classes quanto à coloração do epicarpo e uma coletada diretamente do solo. Para caracterizar a maturidade fisiológica utilizou-se a colorimetria digital e parâmetros biométricos. Nas sementes, determinou-se a massa de matéria seca, o grau de umidade, a germinação, e o índice de velocidade de emergência. As sementes extraídas dos frutos com coloração visual marrom-claro apresentaram maior massa seca, menor teor de água e a porcentagem de germinação e velocidade de emergência, indicando a maturidade fisiológica das sementes. Frutos coletados do chão não são indicados para a coleta de sementes. A colheita dos frutos para obtenção de sementes com maturidade fisiológica é recomendada quando os frutos externarem coloração visual marrom-claro com valores de refratância no espectro visível (RGB) de $96,1,69,9$ e 64,1 , respectivamente.

PALAVRAS-CHAVE: coloração dos frutos, maturação, colheita.

\section{ABSTRACT}

The test aimed to determine the physiological maturity of the seeds from tung nut trees (Aleurites fordii Hemsl.). Ten four-year-old fruits trees were collected in Cascavel - PR. The experiment followed a completely randomized design, with four fruit maturation stages and five replicates with 25 seeds each. The fruits were classified into three classes using the color of the epicarp and collected directly from the ground. To characterize the physiological maturity, digital colorimetric and biometric parameters were utilized. In seeds, the mass of dry matter, moisture content, germination and emergence speed index were determined. The seeds extracted from fruits with light brown eye color had higher dry matter, lower water content and percentage of germination and emergence rate, indicating the physiological maturity of seeds. Fruits collected from the ground are not suitable for seed collection. The harvest of the fruits to obtain seeds with physiological maturity is recommended when the fruits show light brown visual staining reflectance values in the visible spectrum (RGB) of 96.1, 69.9 and 64.1, respectively.

KEYWORDS: coloration of fruits, maturation, crop.

\section{INTRODUÇÃO}

O tungue (Aleurites fordii Hemsl.) é uma planta lenhosa, caducifólia, da família das Euforbiáceas, originária da China. Cultivada para fins de extração de óleo das sementes, o qual é utilizado na indústria química e na produção de biodiesel (RADOMSKI et al. 2007, NAVA et al. 2009).

Apesar de o tungue estar domesticado em outros países da América do Sul, no Brasil ainda é pouco cultivado em escala comercial. As áreas com cultivo situam-se basicamente na região Sul, principalmente no estado do Rio Grande do Sul, no ano de 2011, com aproximadamente 90 ha de cultivo, com produtividade média de $2.500 \mathrm{~kg} \mathrm{ha}^{-1}$ (IBGE 2012).

\footnotetext{
${ }^{1}$ Universidade Estadual do Oeste do Paraná, Marechal Cândido Rondon, PR, Brasil.

${ }^{2}$ Centro Universitário FAG, Cascavel, PR, Brasil.

*Autor para correspondência < paulorikardoo@hotmail.com>
} 
O fruto do tungue é deiscente, carnoso, globoso, liso, apiculado, com a base pedunculada, alguns quase esféricos de 2,5 a $8 \mathrm{~cm}$ de diâmetro, com coloração visual que varia do verde escuro a marrom quando maduros. As sementes têm entre 14 e 35 $\mathrm{mm}$ de comprimento e 15 a $30 \mathrm{~mm}$ de diâmetro com formato próximo a triangular na sua seção transversal, superfície convexa, de coloração castanha, com manchas escuras arredondadas. A semente possui testa espessa (1 a $5 \mathrm{~mm}$ ), lignificada, resultando na restrição a absorção de água, característicos de sementes com dormência física (OLIVEIRA \& PEREIRA 1987, LANGELAND \& BURKS 1998, BARROSO et al. 1999).

$\mathrm{Na}$ implantação de povoamentos da espécie, o plantio de mudas propagadas por sementes é o método mais utilizado (GRUSZYNSKI et al. 2003), o que torna a colheita e a utilização de sementes com qualidade, essenciais para o êxito da atividade.

A maturidade fisiológica das sementes é determinada por fatores genéticos e associados ao desenvolvimento da semente, o qual culmina em potencial fisiológico elevado (MALAVASI 1998). Portanto, a determinação da maturidade fisiológica reveste-se de importância para a colheita, visto que sementes com altos níveis de viabilidade e vigor são requeridas para a produção de mudas com qualidade, assim como a quantificação de parâmetros da cor do fruto tem caráter prático e pode resultar em avanço na mecanização da colheita (MARCOS FILHO 2005, LOPES et al. 2005, CARVALHO \& NAKAGAWA 2012, RUBIO et al. 2013).

Neste sentido, o trabalho objetivou determinar a maturidade fisiológica em sementes de Aleurites fordii Hemsl. utilizando a coloração dos frutos como indicador do momento de colheita.

\section{MATERIAL E MÉTODOS}

Os frutos de Aleurites fordii Hemsl. utilizados no ensaio foram colhidos em abril de 2013 de dez árvores plantadas com quatro anos de idade, cultivadas em espaçamento de $10 \mathrm{~m}$ entre árvores localizadas em Cascavel, PR (2456'27' S; 5330'46,31'” O e 720 m de altitude) em função da coloração do epicarpo.

Os frutos foram classificados pela coloração do epicarpo em quatro estádios (Tabela 1) utilizando-se a escala de cores de Munsell (MUNSELL 1976). O primeiro estádio foi caracterizado por frutos verdes (I), o segundo estádio por frutos verdes iniciando a pigmentação marrom (II), o terceiro estádio por frutos marrom claro (III) colhidos das copas das árvores e o quarto estádio por frutos marrom escuro, coletados no solo (IV).

Tabela 1 - Coloração dos frutos de tungue (Aleurites fordii Hemsl.) em diferentes estádios de maturação.

Table 1 - Staining of tung trees (Aleurites fordii Hemsl.) fruit at different stages of maturation.

\begin{tabular}{cccc}
\hline $\begin{array}{c}\text { Estádio de } \\
\text { maturação }\end{array}$ & $\begin{array}{c}\text { Coloração do } \\
\text { epicarpo }\end{array}$ & $\begin{array}{c}\text { Caracterização } \\
\text { visual }\end{array}$ & Carta de Munsell $^{1}$ \\
\hline I & Verde & $5 \mathrm{GY} 6 / 10$ \\
II & $\begin{array}{c}\text { Início da } \\
\text { pigmentaçao } \\
\text { marrom }\end{array}$ & 10 R 4/2 \\
III & Marrom-claro & 10 R 3/2 \\
IV & Marrom-escuro & 5 YR 3/2 \\
& & &
\end{tabular}

Escala de cores de Munsell (1976). 
Adicionalmente, dez frutos de cada uma das cinco repetições em cada estádio de maturação, foram aferidos quanto à refratância no espectro vermelho, verde e azul utilizando um analisador digital de cor (ACR-1023 Instrutherm ${ }^{\circledR}$ ), seguindo as recomendações de uso do fabricante. Adicionalmente, realizou-se a avaliação biométrica nos mesmos frutos com as mensurações do comprimento e diâmetro (mensurado na região central do fruto), com auxílio de paquímetro digital.

Após as caracterizações colorimétrica e biométrica dos frutos, procedeu-se ao beneficiamento manual para retirada das sementes. O número de sementes foi contabilizado em dez frutos para cada uma das cinco repetições para cada estádio de maturação. Após o beneficiamento, o grau de umidade foi determinado utilizando-se cinco sementes para cada uma das cinco repetições dos estádio de maturação, empregando-se o método de secagem em estufa de circulação de ar a $105 \pm 2{ }^{\circ} \mathrm{C}$ por $24 \mathrm{~h}$, de acordo com as Regras para Análises de Sementes (BRASIL 2009). Conjuntamente, quantificou-se a massa de matéria seca das sementes e massa de matéria seca dos frutos (sem a semente) em balança de precisão $( \pm 0,001 \mathrm{~g})$.

$\mathrm{O}$ teste de germinação foi conduzido com cinco repetições de 25 sementes. Antes da semeadura, as sementes foram escarificadas mecanicamente por excisão na região oposta ao eixo embrionário. As sementes foram semeadas em substrato areia auto clavada, acomodadas em bandejas de polipropileno $(42 \times 28 \times 6 \mathrm{~cm})$ e mantidas em câmara de germinação (B.O.D.) a $25{ }^{\circ} \mathrm{C}$ e $12 \mathrm{~h}$ de luz. Sementes que produziram plântulas eretas, com as folhas cotiledonares completamente expandidas foram consideradas germinadas (BRASIL 2009).

As contagens foram executadas diariamente até a estabilidade da germinação que ocorreu 60 dias após a semeadura. Conjuntamente ao teste de germinação, o índice de velocidade de emergência (IVE) foi calculado de acordo com MAGUIRE (1962).

Após a contagem de plântulas normais, as sementes não germinadas foram submetidas ao teste de tetrazólio a fim de verificar a viabilidade das mesmas. O método seguiu uma adaptação da metodologia proposta por HORING et al. (2011) para Jatropha curcas L. utilizando solução de 2, 3, 5 trifenil cloreto de tetrazólio na concentração de $0,5 \%$ e mantidas em câmara tipo B.O.D a $30^{\circ} \mathrm{C} \pm 2$, na ausência de luz por $4 \mathrm{~h}$.

$\mathrm{O}$ experimento seguiu o delineamento inteiramente ao acaso com quatro tratamentos (estádios de maturação) e cinco repetições. Os dados foram submetidos ao teste de normalidade de Shapiro-Wilk a $5 \%$ de probabilidade, pelo qual não foi verificado necessidade de transformação dos dados. Em seguida os dados foram submetidos a análise de variância e quando da existência de diferenças significativas, as médias foram comparadas pelo teste de Tukey a 5\% de probabilidade, utilizando o programa estatístico ASSISTAT Versão beta 7.6 (SILVA 2012).

\section{RESULTADOS E DISCUSSÃO}

A análise da coloração do epicarpo dos frutos por meio da análise digital de cores revelou diferenças significativas entre os estádios de maturação para os espectros vermelho, verde e azul (Tabela 2). Nota-se que os valores de refratância decresceram à medida que ocorreu avanço na maturação dos frutos. Contudo, não foram detectadas diferenças significativas entre os estádios III e IV. A inexistência de diferenças significativas está associada ao final do processo de maturação, uma vez que o estádio IV caracterizase por frutos em deiscência, coletados do solo, com pigmentos clorofilianos já degradados.

A colheita dos frutos para obtenção de sementes, levando em consideração os valores de refratância poderá facilitar a mecanização da colheita e a segregação de frutos para a obtenção de sementes com maior qualidade fisiológica, dispensando a acuidade visual e o treinamento do colhedor.

Adicionalmente, a colheita de frutos apresentando diferentes estádios de maturação propicia a mistura de sementes com diferentes graus de maturação, prejudicando a qualidade de um lote de sementes. A determinação do ponto de colheita de sementes com base na coloração dos frutos foi recomendada para várias espécies, como em sementes de $J$. curcas (DRANSKI et al. 2010), Erythrina variegata L. (MATHEUS et al. 2011) e Inga laurina (Sw.) Willd. (SCHULZ et al. 2014).

O uso da colorimetria digital foi empregada em frutos de $J$. curcas por DRANSKI et al. (2010) que observaram aderência entre os valores de refratância no espectro vermelho e verde com a maturidade fisiológica das sementes; porém, no espectro azul não foi possível distinção entre os estádios de maturação. Aqueles resultados se mostram contrastante aos observados no presente ensaio, cujos valores nos espectros vermelho, verde e azul foram semelhantes, 
porém com os menores valores obtidos com o avanço no processo de maturação do fruto.

Frutos de A. fordii apresentaram em média quatro sementes por fruto. Com exceção do número de sementes por fruto, a análise de variância revelou haver diferenças significativas $(p<0,05)$ para as variáveis analisadas (Tabela 3).

Frutos colhidos no estádio IV apresentaram valores significativamente menores para o comprimento, diâmetro e massa seca em relação aos frutos colhidos nos estádios I, II e III (Tabela 4). Estes resultados refletem as principais alterações envolvidas durante o processo de deterioração, que abrange o esgotamento das reservas, a alteração da composição química, a oxidação de lipídios, a quebra parcial das proteínas, a alteração das membranas celulares, a redução da integridade e aumento da permeabilidade e desorganização celular, alterações enzimáticas e de nucleotídeos, tenham favorecido as alterações de caráter físico, fisiológico e bioquímico dos frutos (VILLELA \& PERES 2004).

Todas as variáveis analisadas apresentaram distribuição normal dos resíduos pelo teste de Shapiro-Wilk a 5\% de probabilidade. Verificou-se que os dados foram homogêneos com coeficientes de variação que variaram entre $2,61 \%$ para o teor de água das sementes e $27,68 \%$ para o índice de velocidade de emergência.

O maior valor da matéria seca das sementes (MSS) ocorreu em frutos do estádio III $(60,57 \mathrm{~g})$, com incremento de $15 \%$ em comparação aos frutos do estádio I. Frutos do estádio IV resultaram no menor valor $(31,63 \mathrm{~g})$ devido ao processo de deterioração, pois os frutos já haviam sofrido deiscência e expostos às condições do ambiente. A MSS juntamente com outros indicadores foi considerada boa indicadora na determinação da maturidade em sementes de Peltophorum dubium [(Spreng.) Taubert] (AQUINO et al. 2006), Machaerium brasiliense Vogel (GUIMARÃES \& BARBOSA 2007), Caesalpinia echinata Lam. (AGUIAR et al. 2007), J. curcas (DRANSKI et al. 2010) e Inga laurina (Sw.) Willd. (SCHULZ et al. 2014).

A maturidade fisiológica das sementes está associada ao máximo acúmulo de matéria seca, ou seja, a máxima capacidade de translocação de carbono para as sementes, resultando em maior conteúdo de substâncias de reservas (HUNTER et al. 1991, TEKRONY \& EGLI 1997) podendo, no final, sofrer pequeno decréscimo resultante das perdas por respiração e também ao maior poder germinativo das sementes (CARVALHO \& NAKAGAWA 2012).

As sementes de frutos classificados como verdes e início da pigmentação marrom (estádio I e II) apresentaram os maiores teores de água $(47,69$ e 48,18\%, respectivamente). Com o avanço da maturação dos frutos, houve redução, atingindo valores de 39,3\% quando os frutos apresentaram coloração marrom-escuro (estádio IV). Durante a fase de intenso acúmulo de matéria seca o teor de água da semente mantêm-se alto, por ser o veículo responsável pela translocação dos fotoassimilados da planta para a semente.

Não houve diferença significativa $(\mathrm{p}>0,05)$ entre frutos dos estádios I, II e III para a porcentagem de germinação e para o IVE, evidenciando que

Tabela 2 - Valores de refletância de frutos de tungue (Aleurites fordii Hemsl.) obtidos através do analisador digital de cores.

Table 2 - Values of reflectance of fruits of tung trees (Aleurites fordii Hemsl.) obtained using the digital color analyzer.

\begin{tabular}{cccc}
\hline \multirow{2}{*}{ Estádios de maturação } & \multicolumn{3}{c}{ Refratância } \\
\cline { 2 - 4 } & R (Red) & G (Green) & B (Blue) \\
\hline I & $322,6 \mathrm{a}$ & $254,1 \mathrm{a}$ & $128,6 \mathrm{a}$ \\
II & $155,7 \mathrm{~b}$ & $114,7 \mathrm{~b}$ & $98,3 \mathrm{~b}$ \\
III & $96,1 \mathrm{c}$ & $69,9 \mathrm{c}$ & $64,4 \mathrm{c}$ \\
IV & $73,4 \mathrm{c}$ & $51,5 \mathrm{c}$ & $44,4 \mathrm{c}$ \\
\hline C.V. (\%) & 22,63 & 23,26 & 24,90
\end{tabular}

As médias seguidas pela mesma letra não diferem estatisticamente entre si pelo teste Tukey a $5 \%$ de probabilidade. 
Tabela 3 - Resumo da análise de variância dos parâmetros biométricos e de germinação de sementes de tungue (Aleurites fordii Hemsl.) em diferentes estádios de maturação dos frutos.

Table 3 - Summary of variance analysis of biometric parameters and of germination of tung trees (Aleurites fordii Hemsl.) at different stages of maturation.

\begin{tabular}{ccccccccc}
\hline Fonte de & \multicolumn{1}{c}{$F_{\text {calc }}$} & & & & & & & \\
\cline { 2 - 8 } variação & CF & DF & NSF & MVF & MSS & TAS & G & IVE \\
\hline $\begin{array}{c}\text { Estádios de } \\
\text { maturação }\end{array}$ & $19,37^{* *}$ & $28,51^{* *}$ & $1,35^{\text {ns }}$ & $37,70^{* *}$ & $160,37^{* *}$ & $62,22^{* *}$ & $23,51^{* *}$ & $13,46^{* *}$ \\
\hline C.V. (\%) & 6,61 & 5,53 & 19,50 & 17,18 & 4,80 & 2,61 & 20,19 & 27,68 \\
\hline
\end{tabular}

${ }^{* *}$ Significativo ao nível de 1\% de probabilidade; ${ }^{\text {ns }}$ Não significativo pelo teste F. Em que: comprimento de fruto (CF), diâmetro de fruto (DF), número de sementes por fruto (NSF), massa verde de frutos (MVF), massa seca sementes (MSS), teor de água nas sementes (TAS), porcentagem de germinação (G) e índice de velocidade de emergência (IVE).

Tabela 4 - Médias de comprimento de fruto (CF), diâmetro de fruto (DF), massa seca de frutos (MSF), massa seca sementes (MSS), teor de água nas sementes (TAS), germinação (\%G) e índice de velocidade de emergência (IVE) de tungue em função dos estádios de maturação.

Table 4 - Means of fruit length (FL), diameter of fruit (DF), mass dry of fruit (MSF), seed dry mass (MSS), water content in the seeds (TAS), germination $(\% G)$ and index emergency speed (IVE) of tung trees (Aleurites fordii Hemsl.) in function on the stages of maturation.

\begin{tabular}{cccccccc}
\hline Tratamentos & $\begin{array}{c}\text { CF } \\
(\mathrm{mm})\end{array}$ & $\begin{array}{c}\text { DF } \\
(\mathrm{mm})\end{array}$ & $\begin{array}{c}\text { MSF } \\
(\mathrm{g})\end{array}$ & $\begin{array}{c}\text { MSS } \\
(\mathrm{g})\end{array}$ & $\begin{array}{c}\text { TAS } \\
(\%)\end{array}$ & $\begin{array}{c}\text { G } \\
(\%)\end{array}$ & IVE \\
\hline I & $57,77 \mathrm{a}$ & $54,95 \mathrm{ab}$ & $65,34 \mathrm{a}$ & $40,43 \mathrm{c}$ & $47,69 \mathrm{a}$ & $36,8 \mathrm{a}$ & $0,229 \mathrm{a}$ \\
II & $57,95 \mathrm{a}$ & $56,68 \mathrm{a}$ & $68,74 \mathrm{a}$ & $46,28 \mathrm{~b}$ & $48,18 \mathrm{a}$ & $41,6 \mathrm{a}$ & $0,292 \mathrm{a}$ \\
III & $56,31 \mathrm{a}$ & $52,86 \mathrm{~b}$ & $61,60 \mathrm{a}$ & $60,57 \mathrm{a}$ & $43,72 \mathrm{~b}$ & $44,0 \mathrm{a}$ & $0,295 \mathrm{a}$ \\
\hline IV & $47,36 \mathrm{~b}$ & $45,54 \mathrm{c}$ & $28,3 \mathrm{~b}$ & $31,63 \mathrm{~d}$ & $39,33 \mathrm{c}$ & $12,0 \mathrm{~b}$ & $0,078 \mathrm{~b}$
\end{tabular}

Médias seguidas pela mesma letra na coluna não diferem estatisticamente entre si pelo teste de Tukey ao nível de $5 \%$ de probabilidade.

sementes de $A$. fordii oriundas de frutos verdes possuíam capacidade de estabelecer uma plântula normal. Porém, frutos que apresentaram coloração marrom-escuro (estádio IV) apresentaram a menor porcentagem de germinação (12\%) provavelmente devido à deterioração.

Apesar dos frutos nos estádios I e II apresentarem germinação semelhante ao estádio $\mathrm{IV}$, estes apresentavam dificuldade de remoção das sementes dos frutos, tornando praticamente inviável sua utilização para obtenção de sementes a campo.

Os resultados do teste de tetrazólio com as sementes não germinadas indicaram que aquelas provenientes de frutos do estádio I apresentaram maior número de sementes ainda viáveis $(26,4 \%)$ e as sementes obtidas de frutos no estádio III o menor valor $(17,4 \%)$.
Sementes de frutos no estádio IV apresentaram menor taxa de germinação e entre as não germinadas $51,9 \%$ estavam vazias, podres, danificadas ou mortas, $23,1 \%$ eram inviáveis e o restante $(25 \%)$ ainda se encontravam viáveis. A capacidade germinativa representa o principal parâmetro a ser considerado no estudo da maturação, pois, sem ela, a semente não tem valor para a semeadura, e dela também dependem a qualidade das mudas e o sucesso de um reflorestamento (GONÇALVES et al. 2008).

O número de sementes consideradas mortas se elevou à medida que avançou o grau de deterioração e sementes de frutos recolhidos no chão (estádio IV) apresentaram a maior proporção de sementes mortas, devido à exposição a inúmeros fatores físicos e biológicos que podem causar sua deterioração e perda do poder germinativo. MARCOS FILHO (2005) 
relatou o processo de deterioração sendo determinado por uma série de alterações fisiológicas, bioquímicas, físicas e citológicas, com início a partir da maturidade fisiológica, em ritmo progressivo, determinando a queda da qualidade e culminando com a morte da semente.

Sementes obtidas de frutos com coloração marrom-claro mostraram melhor qualidade fisiológica, apresentando maior germinação e vigor, menores teores de água, e maior conteúdo de matéria seca, sendo estes, indicadores do momento ideal de colheita. Já sementes obtidas de frutos coletados no solo estavam sob forte processo de deterioração e perda de viabilidade não sendo recomendadas para fins propagativos.

\section{CONCLUSÃO}

Os frutos do estádio III, classificados como 10 R 3/2 na escala de cores de Munsell e com valores de refletância de 96, 70 e $64 \mathrm{~nm}$ na escala do vermelho, verde e azul, respectivamente, que correspondem à coloração marrom-claro colhidos diretamente da planta produzem sementes com maturidade fisiológica indicativo do momento ideal de colheita.

Ainda no estádio III, sementes apresentam maior teor de matéria seca e redução no teor de água e maior facilidade na extração das sementes dos frutos, em relação aos estádios I e II.

\section{REFERÊNCIAS}

AGUIAR FFA et al. 2007. Maturação de frutos de Caesalpinia echinata Lam. Pau-Brasil. Revista Árvore 31:1-6.

AQUINO NF et al. 2006. Dormência de sementes de Peltophorum dubium (Sprengel.) Taubert colhidas em diferentes estádios de desenvolvimento. Scientia Agraria Paranaensis 5:31-37.

BARROSO GM et al. 1999. Frutos e Sementes: morfologia aplicada à sistemática de dicotiledôneas. Viçosa: Editora UFV. 443p.

BRASIL. 2009. Ministério da Agricultura, Pecuária e Abastecimento. Regras para análise de sementes. Brasília: Secretaria de Defesa Agropecuária, Mapa/ACS. 399p.

CARVALHO NM \& NAKAGAWA J. 2012. Sementes: ciência, tecnologia e produção. 5.ed. Jaboticabal: FUNEP. 590p.

DRANSKI JAL et al. 2010. Physiological maturity of seeds and colorimetry of fruits of Jatropha curcas L. Revista Brasileira de Sementes 32:158-165.

GONÇALVES EP et al. 2008. Testes de vigor em sementes de Guazuma ulmifolia Lam. Semina. Ciências Agrárias 29:265-276.

GRUSZYNSKI C et al. 2003. Misturas de casca de tungue e casca de arroz carbonizada no enraizamento de Dendranthema morifolium Tzevelev 'golden polaris' sob método de transpiração. Revista Brasileira de Horticultura Ornamental 9:63-70.

GUIMARÃES DM \& BARBOSA JM. 2007. Coloração dos frutos como índice de maturação para sementes de Machaerium brasiliense Vogel (Leguminosae - Fabaceae). Revista Brasileira de Biociências 5:567-569.

HORING CF et al. 2011. Armazenamento não controlado na qualidade de sementes de Jatropha curcas L. Semina. Ciências Agrárias 32:521-526.

HUNTER JL et al. 1991. Corn seed maturity indicators and their relationship to uptake of Carbon-14 assimilate. Crop Science 31:1309-1313.

IBGE - INSTITUTO BRASILEIRO DE GEOGRAFIA E ESTATÍSTICA. 2012. Produção Agrícola Municipal: Culturas temporárias e permanentes. Rio de Janeiro: IBGE. p.1-101.

LANGELAND KA \& BURKS KC. 1998. Identification and Biology of Non-Native Plants in Florida's Natural Areas. IFAS Publication SP 257. University of Florida, Gainesville. 165p.

LOPES JC et al. 2005. Maturação fisiológica de sementes de quaresmeiras. Pesquisa Agropecuária Brasileira 40:811816.

MAGUIRE JD. 1962. Speed of germination-aid in selection and evaluation for seedlig emergence and vigor. Crop Science 2:176-177.

MALAVASI MM. 1998. Germinação de sementes. In: PIÑA-RODRIGUES, FCM (Coord.). Manual de análise de sementes florestais. Campinas: Fundação Cargill, p. 25-40. MARCOS FILHO J. 2005. Fisiologia de sementes de plantas cultivadas. Piracicaba: FEALQ, 495p.

MATHEUS MT et al. 2011. Maturação fisiológica de sementes de Erythrina variegata L. Ciência Florestal 21: 619-627.

MUNSELL AH. 1976. Munsell book of color. Baltimore: Macbeth Division of Kollmorgen, 20p.

NAVA DE et al. 2009. Insetos pragas e benéficos na cultura do tungue. Pelotas: EMBRAPA - Empresa Brasileira de Pesquisa Agropecuária Clima Temperado. Documentos, 276, 16p.

OLIVEIRA EC \& PEREIRA TS. 1987. Euphorbiaceae morfologia da germinação de algumas espécies. Revista Brasileira de Sementes 9:9-29.

RADOMSKI MI et al. 2007. Introdução do tungue (Aleurites fordii) em sistemas agroflorestais de agricultores familiares agroecológicos da região da Floresta com Araucária, no Paraná. Revista Brasileira de Agroecologia 2:1066-1069.

RUBIO F et al. 2013. Estádios de maturação do fruto no desempenho germinativo e teor de óleo de sementes de 
Jatropha curcas Linn. Semina: Ciências Agrárias 34:663668.

SCHULZ DG et al. 2014. Maturidade Fisiológica e Morfometria de Sementes de Inga laurina (Sw.) Willd. Floresta e Ambiente 21:45-51.

SILVA FAS. 2012. Sistema de Assistência Estatística ASSISTAT versão 7.6 beta. Departamento de Engenharia Agricola (DEAG) do CTRN da Universidade Federal de Campina Grande - UFCG, Campina Grande, PB.

TEKRONY DM \& EGLI DB. 1997. Accumulation of seed vigour during development and maturation. Basic and Applied Aspects of Seed Biology 30:369-384.

VILLELA FA \& PERES WB. 2004. Coleta, beneficiamento e armazenamento. In: FERREIRA, AG. e BORGHETTI, F. (Ed.). Germinação: do básico ao aplicado.Porto Alegre: Artmed, p.323. il. 